\title{
EFEITO DA CONCENTRAÇÃO DE SÓLIDOS E DO PH NA REOLOGIA DE SUSPENSÕES
}

\author{
OLIVEIRA, B.R. ${ }^{1}$, KLAIMI,R. ${ }^{2}$, FERRAZ, A.S.F.S ${ }^{3}$, MARQUES, M.R.C. ${ }^{3}$, SCHEID, C.M. ${ }^{1}$ \\ e CALÇADA, L.M. ${ }^{1}$ \\ ${ }^{1}$ Universidade Federal Rural do Rio de Janeiro, Departamento de Engenharia Química \\ ${ }^{2}$ American University of Beirute, Departamento de Engenharia Química \\ ${ }^{3}$ Universidade Estadual do Rio de Janeiro, Departamento de Engenharia Química \\ E-mail para contato: oliveira.biarosas@gmail.com
}

\begin{abstract}
RESUMO - As funções dos fluidos de perfuração são diretamente dependentes de suas propriedades físicas, químicas e reológicas. A presença de agentes viscosificantes, sólidos adensantes e obturantes contribui para o controle do comportamento reológico dos fluidos. Logo, a composição do fluido é selecionada e controlada a fim de se obter o melhor desempenho da perfuração de poços de petróleo. neste trabalho, busca-se avaliar a influência da concentração de sólidos e da variação do ph no comportamento reológico de suspensões de carboximetilcelulose e dolomita branca. Os resultados mostraram que o aumento da concentração de sólidos aumentou a viscosidade aparente das suspensões devido às interações químicas entre o polímero e as partículas de dolomita branca. As suspensões com $\mathrm{pH}$ menor que 5 apresentaram menores valores de tensão de cisalhamento e viscosidade aparente indicando interações entre os íons $\mathrm{H}^{+}$e o polímero aniônico. A formação de agregados de dolomita branca causa uma diminuição da viscosidade da suspensão.
\end{abstract}

\section{INTRODUÇÃO}

Os fluidos de perfuração são sistemas líquidos multifásicos formados por sólidos em suspensão e polímeros dissolvidos em água, entre outros compostos. Esses fluidos são indispensáveis, pois desempenham diversas funções essenciais para as atividades de perfuração. Estas funções são dependentes de suas propriedades físicas, químicas e reológicas. De acordo com Thomas et al. (2001), a composição dos fluidos é o principal fator a se considerar no controle de suas propriedades.

Logo, torna-se essencial controlar as propriedades reológicas do fluido a fim de aperfeiçoar a perfuração e minimizar a invasão do fluido através das formações produtoras (Vital, 2005). Segundo Ortega et al. (1997), os maiores contribuintes para o comportamento reológico de uma suspensão são as propriedades do fluido base e dos sólidos. Entre os fatores que influenciam a reologia do sistema estão: concentração de sólidos, densidade do meio líquido e dos sólidos, temperatura, características físicas das partículas e o tipo de interação entre elas.

Um dos aditivos viscosificantes mais utilizados é a carboximetilcelulose (CMC). O uso deste polímero de caráter aniônico reduz as perdas por filtração produzindo rebocos muito finos, além de aumentar a viscosidade do fluido (Hughes et al., 1993). 
$\mathrm{O}$ efeito do $\mathrm{pH}$ na reologia está diretamente relacionado com as interações entre as partículas. Em operações de perfuração a lama alcalina é a mais utilizada (pH igual ou maior que 9). A soda cáustica e o hidróxido de sódio são utilizados para se reduzir a acidez do fluido. Fluidos com caráter ácido podem causar a corrosão das ferramentas de perfuração enquanto que esta se torna menos agressiva com fluidos alcalinos (Santos, 2012).

Torrance e Pirmat (1984) concluíram que à medida que o $\mathrm{pH}$ de suspensões com argila marinha diminui, a tensão limite de escoamento aumenta. Mas após atingir $\mathrm{pH}$ igual a 5,5, a tensão se reduz. Khandal e Trados (1998) concluíram que em uma faixa de pH ácida houve maior interação entre as partículas em suspensões de montmorilonita sódica.

Neste trabalho, pretende-se avaliar a influência da concentração de sólidos e da variação do $\mathrm{pH}$ no comportamento reológico de suspensões de carboximetilcelulose e dolomita branca. Para fins fundamentais trabalharemos também em uma faixa ácida.

\section{MATERIAIS E MÉTODOS}

\subsection{Difratometria de Raio-X}

A técnica de difração de raios $X$ foi utilizada para caracterização química e mineralógica das partículas de dolomita branca (AMC Brasil Minas) e CMC (System Mud). Os difratogramas de raios $X$ foram obtidos operando-se com radiação de Co Ka a $15 \mathrm{~mA}$ e 30 $\mathrm{kV}$. A varredura foi conduzida com intervalos de $0,050^{\circ}$ de 1,1 a $60^{\circ}$ (20) e tempo de aquisição de 2 s.

\subsection{Determinação da granulometria}

A fim de separar as partículas de dolomita branca em uma mesma faixa granulométrica, foi utilizado um agitador eletromagnético com peneiras (marca Bertel). A caracterização do tamanho das partículas foi obtida em um analisador de partículas Malvern Mastersizer Hydro 2000 UM utilizando a técnica de difração a laser.

\subsection{Preparo dos fluidos não-Newtonianos}

Os fluidos foram preparados com o polímero carboximetilcelulose e diferentes concentrações de dolomita branca com posterior variação no $\mathrm{pH}$. Primeiramente, foi preparada uma solução de água deionizada $(\mathrm{pH} \approx 7)$ e o polímero com concentração de 2 lb/bbl. Um agitador mecânico Fisatom modelo 722 foi utilizado à $1700 \mathrm{rpm}$ durante 20 minutos até a completa homogeneização da solução. Em seguida o fluido foi pesado em uma balança de lama Fann modelo 140 a fim de determinar a quantidade de dolomita branca necessária para alcançar as densidades de 9, 9,5 e $10 \mathrm{lb} / \mathrm{gal}$ em $350 \mathrm{~mL}$ de suspensão. Os fluidos foram novamente agitados durante 20 minutos até a completa homogeneização.

A fim de avaliar a influência do $\mathrm{pH}$, as três suspensões foram novamente divididas totalizando nove amostras de mesmo volume. Em ambas densidades, uma amostra foi acidificada com ácido clorídrico concentrado, em outra gotas de solução de hidróxido de sódio $0,1 \mathrm{M}$ foram adicionadas e na última o $\mathrm{pH}$ não foi alterado. Aferiu-se o $\mathrm{pH}$ das nove amostras em um pHmetro Bel Modelo W3B. 


\subsection{Estudo reológico}

Os testes reológicos foram realizados a $25^{\circ} \mathrm{C}$ em um reômetro Haake RheoStress 1 da Thermo Scientific. Os ensaios foram realizados com a geometria do tipo cilindros coaxiais utilizando copo de medição DG43 e rotor cilíndrico DG43-Ti. A taxa de deformação foi controlada, variando no intervalo de 0 a $1021 \mathrm{~s}^{-1}$ com duração de $120 \mathrm{~s}$.

\section{RESULTADOS E DISCUSSÕES}

\subsection{Caracterização mineralógica}

As Figuras 1 e 2 representam respectivamente os difratogramas de raio $\mathrm{X}$ do polímero $\mathrm{CMC}$ e da dolomita branca.

Figura 1 - Difratograma de raios $\mathrm{X}$ (CMC).

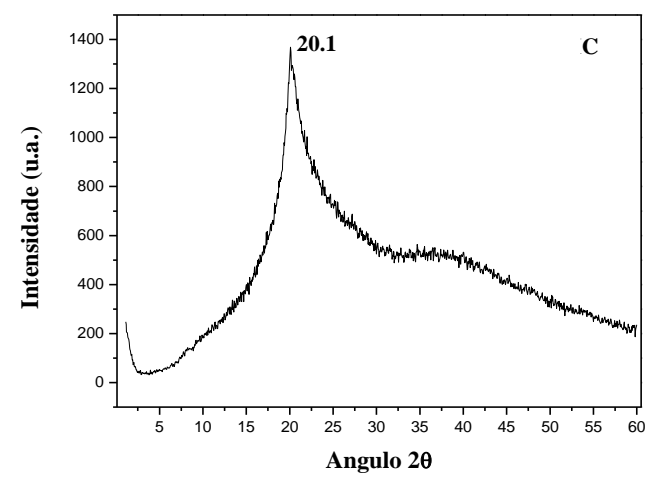

Figura 2 - Difratograma de raios X (dolomita branca).

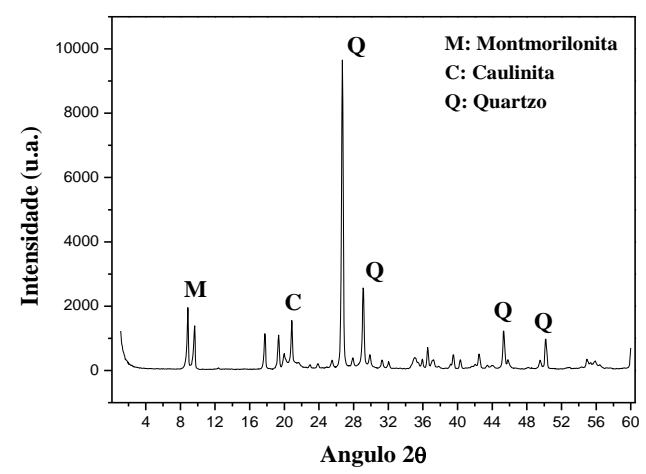

O polímero CMC é caracterizado por único pico em $2 \theta$ a aproximadamente $20^{\circ}$ (Sartor et al., 2012). Enquanto que a dolomita branca é constituída dos minerais montmorilonita, quartzo e caulinita.

\subsection{Caracterização granulométrica}

A Figura 3 apresenta a distribuição granulométrica da dolomita branca. Este sólido é constituído de partículas pequenas com um intervalo de tamanho de $0-73 \mu \mathrm{m}$.

Figura 3 - Distribuição granulométrica da dolomita branca.

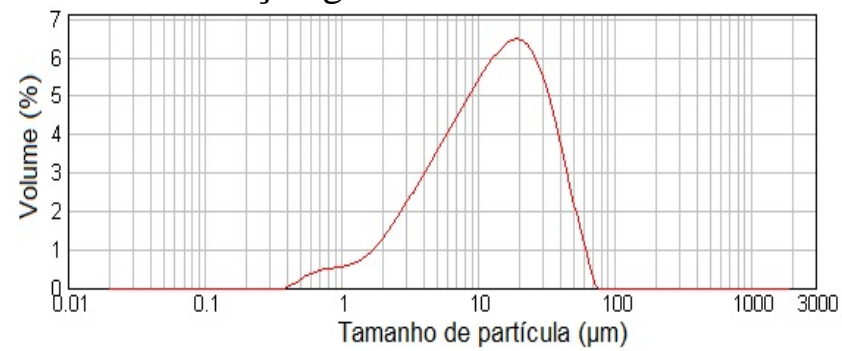


Na Tabela $1, D_{10}, D_{50}$ e $D_{90}$ representam o tamanho de partícula $(\mu \mathrm{m})$ de dolomita branca abaixo do qual se situam respectivamente $10 \%, 50 \%$ e $90 \%$ das partículas e Ds é o diâmetro médio de Sauter.

Tabela 1 - Parâmetros obtidos na caracterização dos sólidos

\begin{tabular}{|c|c|c|c|c|}
\hline Material & $\begin{array}{c}\mathrm{D}_{10} \\
(\mu \mathrm{m})\end{array}$ & $\begin{array}{c}\mathrm{D}_{50} \\
(\mu \mathrm{m})\end{array}$ & $\begin{array}{c}\mathrm{D}_{90} \\
(\mu \mathrm{m})\end{array}$ & $\begin{array}{c}\mathrm{Ds} \\
(\mu \mathrm{m})\end{array}$ \\
\hline $\begin{array}{c}\text { Dolomita } \\
\text { branca }\end{array}$ & 2,951 & 13,154 & 36,448 & 8,978 \\
\hline
\end{tabular}

\subsection{Caracterização do pH}

A Tabela 2 apresenta os valores aferidos de potencial hidrogeniônico $(\mathrm{pH})$ para as suspensões de CMC e dolomita branca com diferentes densidades.

Tabela 2 - Caracterização do pH das suspensões

\begin{tabular}{|c|c|c|c|}
\hline $\begin{array}{c}\text { Densidade / } \\
\text { Tipo de } \\
\text { suspensão }\end{array}$ & $\begin{array}{c}9 \\
(\mathrm{lb} / \mathrm{gal})\end{array}$ & $\begin{array}{c}9,5 \\
(\mathrm{lb} / \mathrm{gal})\end{array}$ & $\begin{array}{c}10 \\
(\mathrm{lb} / \mathrm{gal})\end{array}$ \\
\hline Ácida & 4,77 & 4,58 & 4,7 \\
\hline Neutra & 7,14 & 7,3 & 7,09 \\
\hline Básica & 8,9 & 9 & 9,4 \\
\hline
\end{tabular}

\subsection{Reologia}

A Figura 4 apresenta as curvas de viscosidade aparente e tensão de cisalhamento para as suspensões de dolomita branca e CMC com densidades de 9, 9,5 e $10 \mathrm{lb} / \mathrm{gal}$.

Figura 4 - Viscosidade aparente e Tensão de cisalhamento versus taxa de deformação (suspensões $\mathrm{CMC}$ /dolomita branca).

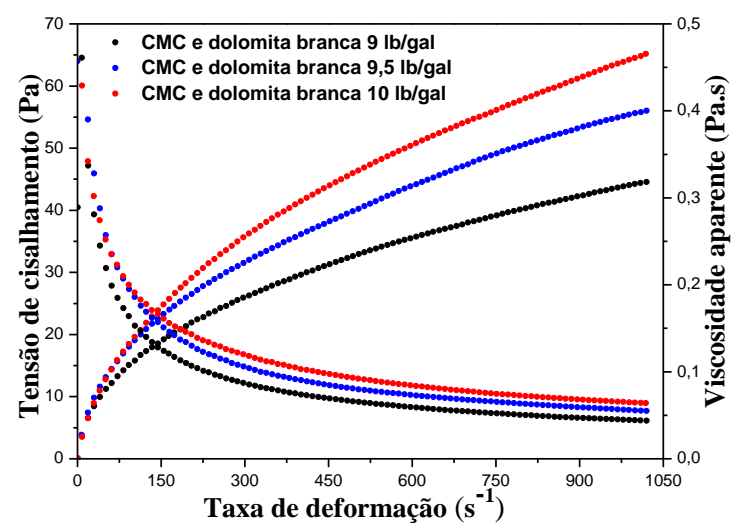

Pode-se observar que a viscosidade aparente dessas suspensões aumentou com o aumento da concentração de dolomita branca em uma taxa de deformação constante. A viscosidade de fluidos de perfuração é dependente de partículas sólidas presentes e de sua forma (Alaskari e Teymoori, 2007). 


\section{Congresso Brasileiro de Engenharia Química em Iniciação Científica UFSCar - São Carlos - SP 16 a 19 de Julho de 2017}

$\mathrm{Na}$ presença do polímero CMC, essas partículas formam cadeias moleculares que causam um aumento da viscosidade aparente da suspensão. Com um maior número de partículas, mais cadeias serão formadas resultando em uma maior resistência ao fluxo.

As Figuras 5, 6 e 7 apresentam as curvas de viscosidade aparente para as suspensões com diferentes potenciais hidrogeniônicos com valores de densidade de 9, 9,5 e $10 \mathrm{lb} / \mathrm{gal}$, respectivamente.

Figura 5 - Viscosidade aparente versus taxa de deformação (suspensões CMC/dolomita branca $9 \mathrm{lb} / \mathrm{gal})$.

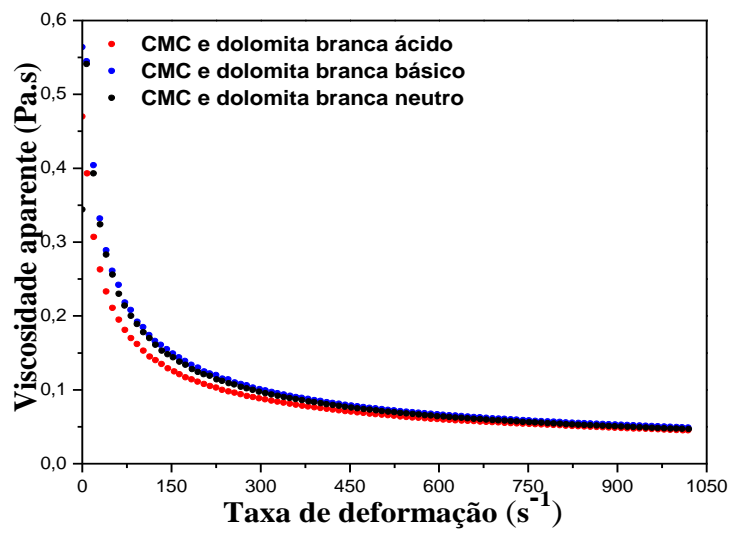

Figura 6 - Viscosidade aparente versus taxa de deformação (suspensões CMC/dolomita branca $9,5 \mathrm{lb} / \mathrm{gal})$.

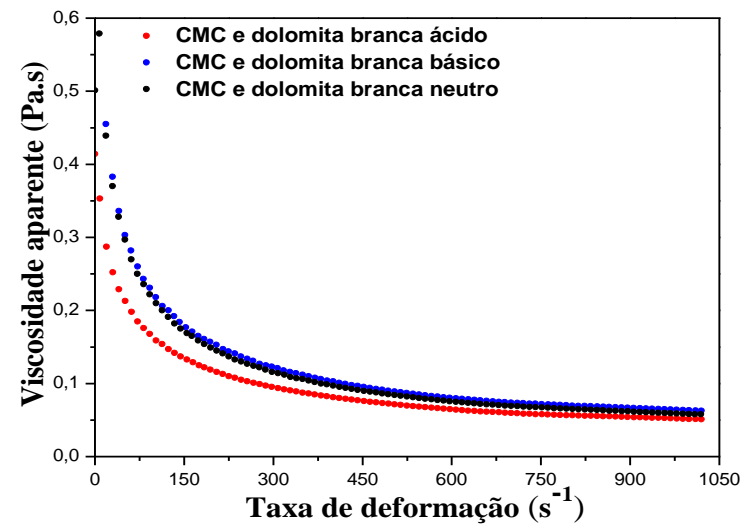

Figura 7 - Viscosidade aparente versus taxa de deformação (suspensões CMC/dolomita branca $10 \mathrm{lb} / \mathrm{gal})$.

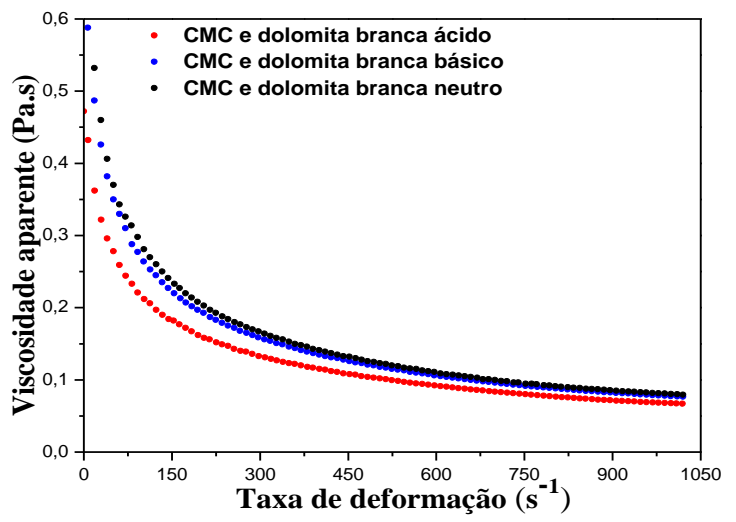

Nas três densidades estudadas, as suspensões com pH ácido apresentaram as menores viscosidades aparentes. Este comportamento pode ser explicado pela protonação dos grupos carboxílicos da CMC, resultando num aumento da hidrofobicidade deste polímero e subsequente redução da molhabilidade da dolomita branca. Logo, essa formação de agregados de dolomita branca causa a diminuição da viscosidade da suspensão. 


\section{CONCLUSÕES}

As suspensões com maiores concentrações de dolomita branca apresentaram maiores valores de viscosidade aparente e tensão de cisalhamento.

A adição de ácido alterou as curvas de escoamento e de viscosidade aparente das suspensões, enquanto que não foi possível observar um significativo efeito da adição de base. As suspensões acidificadas apresentaram menores valores de tensão cisalhante e viscosidade aparente.

\section{REFERÊNCIAS}

ALASKARI, M.K.G., TEYMOORI, R.N, Effects of salinity, $\mathrm{pH}$ and temperature on CMC polymer and XC polymer performance. IJE Transactions B: Applications, v. 20(3): p. 283-290, 2007.

HUGHES, T. L., JONES T. G. J., HOUWEN O. H. SPE Drilling \& Completion, p. 157-163, 1993.

KHANDAL, R. K., TADROS, T. F. Application of viscoelastic measurements to the investigation of the swelling of sodium montmorillonite suspensions. J. Colloid Interface Sci., 125, p. 122-128, 1988.

ORTEGA, F. S., PADOLFELli, V.C., RODRIGUES, J. A., SOUZA, D. P. F. Aspectos da reologia e da estabilidade de suspensões. Parte I: fundamentos. Revista Cerãmica, v. 43, 1997.

SANTOS, M.B. Perfuração de poços de petróleo: fluidos de perfuração. Revista de divulgação do Projeto Universidade Petrobras e IF Fluminense, v. 2, n. 1, p. 121-127, 2012.

SARTOR, G.B., EVSSEV, I., BURGARDT, V. C. F., OLIVEIRA, D. F. Uso da técnica de difração de raios-X para avaliação da interação de biopolímeros. Sicite XVII, 2012.

THOMAS J. E. Fundamentos de Engenharia de Petróleo. Rio de Janeiro: PETROBRAS, p. $271,2001$.

TORRANCE, K. J., AND PIRMAT, M. Effect of pH on the Rheology of Marine Clay from the Site of the South Nation River, Clays Clay Miner, v. 32(5), p. $384-390,1984$.

VITAL, G. S. Seleção de tensoativos e influência de um estabilizante para a otimização de formulações de fluidos de perfuração à base de óleo vegetal, Monografia. Universidade Federal do Rio Grande do Norte, Natal, p. 50, 2005. 